\title{
Penggunaan Model Pembelajaran Berbasis Collaborative Learning Berpengaruh terhadap Hasil Belajar Akuntansi
}

\author{
Rosmiati \\ Pendidikan Ekonomi, Jurusan PIPS FKIP, Universitas Jambi \\ Correspondence email: rosmiati.fkip@unja.ac.id
}

\begin{abstract}
Penyebab rendahnya ketuntasan belajar pada mata pelajran akuntansi karena model pembelajaran yang digunakan di kelas tidak tepat dan kurangnya media pembelajaran sehingga mengakibatkan siswa kurang tertarik untuk belajar dan berimplikasi pada kurangnya pemahaman siswa terhadap materi dan hasil belajar itu sendiri. Tujuan dilakukannya penelitian ini adalah untuk mengetahui pengaruh penggunaan model pembelajaran berbasis collaborative learning terhadap hasil belajar akuntansi siswa kelas XI IPS SMA Negeri 5 Kota Jambi. Penelitian ini menggunakan pendekatan eksperimen semu dengan bentuk desain pretestpostest control group comparision design. Subjek dalam penelitian ini adalah siswa kelas XI IPS 5 sebagai kelas eksperimen dan XI IPS 3 sebagai kelas kontrol dengan teknik analisis data hasil belajar menggunakan uji t-test. Maka dapat disimpulkan bahwa rata-rata hasil belajar akuntansi siswa kelas XI IPS yang diajarkan dengaii menggunakan model pembelajaran berbasis Collaborative Learning adalah 75,33 lebih tinggi dibandingkan dengan rata-rata hasil belajar siswa kelas XI IPS pada mata pelajaran akuntansi yang diajarkan secara konvensional adalah 62,8. Hasil uji t-test diperoleh hasil kooefisien $t_{\text {hitung }}>t_{\text {tabel }}$ atau $5,048>2,039$. Dengan demikian dapat diartikan terdapat pengaruh penggunaan model pembelajaran berbasis Collaborative Learning terhadap hasil belajar akuntansi siswa kelas XI IPS SMA Negeri 5 Kota Jambi.
\end{abstract}

Kata Kunci: Model Pembelajaran Berbasis Collaborative Learning, Hasil Belajar

\begin{abstract}
The cause of the low completeness of learning in accounting subjects is due to the inappropriate learning model used in the classroom and the lack of learning media which results in students being less interested in learning and it has implications for students' lack of understanding of the material and learning outcomes themselves. The purpose of this study was to determine the effect of using a collaborative learning-based learning model on the accounting learning outcomes of students in class XI IPS at SMA Negeri 5 Jambi City. This study used a quasi-experimental approach with a pretest-posttest control group comparision design. The subjects in this study were students of class XI IPS 5 as the experimental class and XI IPS 3 as the control class with the data analysis technique of learning outcomes using the t-test. So it can be concluded that the average accounting learning outcomes of class XI IPS students who are taught using a Collaborative Learning-based learning model is 75.33 higher than the average learning outcomes of class XI IPS students in accounting subjects taught conventionally is 62., 8. The results of the t-test showed that the coefficient tcount> ttable or 5.048> 2.039. Thus it can be interpreted that there is an effect of the use of Collaborative Learning-based learning models on the learning outcomes of accounting students in class XI IPS at SMA Negeri 5 Jambi City.
\end{abstract}

Keywords: Collaborative Learning Based Learning Model, Learning Outcomes

\section{PENDAHULUAN}

Dari waktu kewaktu perkembangan ilmu pengetahuan dan teknologi semakin pesat. Arus globalisasi juga semakin hebat. Akibat dari fenomena ini muncul persaingan dalam berbagai bidang kehidupan, diantaranya bidang pendidikan. Untuk menghadapi tantangan berat ini dibutuhkan sumber daya manusia yang berkualitas. Salah satu cara yang ditempuh adalah melalui peningkatan mutu pendidikan (Darsono, 2000:1).

Kardiman (2006:03) berpendapat karakteristik pembelajaran akutansi, adalah suatu pembelajaran yang bersifat prosedural atau satu tahap itu berhubungan dan menjadi syarat dalam mengerjakan tahap berikutnya. Sebagai contoh materi pencatatan junial umum itu berhubungan dan akan menjadi syarat dalam mengerjakan materi buku besar, Oleh karena itu, peserta didik (siswa) dituntut untuk bisa menguasai setiap tahapan dalam materi akuntansi agar bisa mempelajari semua materi pelajaran akuntansi secara tuntas. Hal ini diperlukan untuk bisa memberi ketrampilan atau pengetahuan akuntansi kepada peserta didik (siswa) (Patel, 2010:30) melalui pembelajaran kolaboratif

Fungsional dalam mencoba untuk keterampilan koordinasi, to coordinate skills, tools, and rewards. Belajar kolaboratif menuntut adanya modifikasi tujuan pembelajaran dari yang semula sekedar penyampaian informasi menjadi konstruksi pengetahuan oleh individu melalui belajar kelompok. Dalam belajar kolaboratif, tidak ada perbedaan tugas untuk masing-masing individu, melainkan tugas itu milik bersama dan diselesikan secara bersama tanpa membedakan percakapan belajar siswa.

Hal yang sama juga dikatakan oleh Jonassen (1996:21) bahwa belajar secara kolaboratif dapat membuat siswa saling bekerja sama dengan saling bantu membantu dalam menyelesaikan masalah pembelajaran. Selain itu dengan dibentuk kolaborasi, maka peserta didik yang kurang berminat belajar maka secara otomatis akan lebih termotivasi 
oleh teman satu kelompoknya yang rajin. Dan jika dibentuk kelompok maka ide akan lebih berkembang, dimana setiap peserta didik dalam kelompok pasti memiliki ide masing-masing, jika ide tersebut dipilah dan disatukan tentunya produktivitas dan kreativitas kelompok akan tinggi.

Marianus, (1998:08) Berpendapat bahwa Hasil belajar Akuntansi adalah hasil belajar yang didapatkan siswa setelah mempelajari pelajaran akutansi dan dapat memahami masalah-masalah yang terjadi dalam pelajaran akutansi, siwa juga dapat memahami prinsip-prinsip dasar akutansi yang benar dan sesuai dengan arahan Bahan Standar Nasional Pendidikan. Hasil belajar akutansi dapat diketahui setelah kegiatan pemberian tugas setiap selesai pemberian mated, karena sifat pelajaran akutansi bersifat kesinabunagan atau melalui tahap satu ke tahap berikutnya dan jika ada salah satu materi bab yang ditinggalkan untuk memahami materi selanjutnya siswa akan kebingungan dan tidak paham. jadi guru harus teliti dalam mengajar akutansi, setiap selesai menjelaskan materi harus diberikan latihanlatihan yang bersifat berurutan dari soal latihan yang mudah,sedang,hingga yang paling sulit. Agar mendapatkan hasil belajar yang diinginkan.

\section{METODE}

Penelitian ini termasuk dalam penelitian eksperimen semu (quasi experiment). Menurut Sugiyono (2012:114), bentuk desain eksperimen ini merupakan pengembangan dari true experimental design. Desain ini mempunyai kelompok kontrol, tetapi tidak dapat berfungsi sepenuhnya untuk mengontrol variabel- variabel luar yang mempengaruhi pelaksanaan eskperimen.

Untuk menguji hipotesis yang diajukan, yaitu pengaruh penggunaan model pembelajaran berbasis Collaborative learning terhadap hasil belajar akuntansi siswa kelas XI IPS SMA Negri 5 kota Jambi, maka dilakuakan dengan membedakan rata-rata hasil belajar antara kelas kelompok kelas eksperimen dengan kelompok kelas kontrol . jika terdapat perbedaan dimana nilai rata-rata (mean) kelas eksperimen lebih besar dari rata-rata (mean) kelas kontrol berarti model pembelajaran berbasis collaborative learning yang diterapkan berpengaruh terhadap peningkatan hasil belajar siswa.

Teknik statistik yang digunakan untuk menguji hipotesis tersebut adalah $\mathrm{t}$ - test separated varians fSugiono,2012:138) sebagai berikut :

$$
\mathrm{t}=\frac{X 2 \square X 2}{\sqrt{\frac{S_{1}^{1}}{n_{1}}+\frac{S_{2}^{2}}{n_{2}}}}
$$

Keterangan :

$\mathrm{X}_{1} \quad=$ Skor rata-rata kelas eksperimen

$\mathrm{X}_{2} \quad=$ Skor rata-rata kelas kontrol

$\mathrm{S}^{\wedge} \quad=$ Varian hasil belajar kelas kontrol

$82=$ Varian hasil belajar kelas eksperimen

$\% \quad=$ Jumlah sampel kelas kontrol

$\mathrm{n}_{2} \quad=$ Jumlah sampel kelas eksperimen

Kriteria pengujian adalah jika $t_{\text {hitung }}<\mathrm{t}_{\text {tabel }}$ maka Ho ditolak dan Ha di terima sedangkan jika $t_{\text {hitung }}<\mathrm{t}_{\text {tabel }}$ maka Ho diterima dan Ha ditolak untuk taraf nyata $=0,05$ dengan $\mathrm{dk}=n_{1}+\mathrm{n}_{2}-2$ dengan peluang untuk penggunaan daftar distribusi t ialah ( $1-a)$.

\section{HASIL DAN PEMBAHASAN}

Setelah dilakukan penelitian tentang Pengaruh penggunaan Model Pembelajaran berbasis Collaborative Learning terhadap Hasil Belajar Akuntansi Siswa pada Kelas XI IPS SMA Negeri 5 Kota Jambi diperoleh hasil yang meliputi deskripsi data, analisis data dan pembahasan.

Berdasarkan data yang telah diperoleh, ternyata distribusi data hasil belajar kelas eksperimen menyebar dari 61,5 sampai 88,5 berdasarkan distribusi skor tersebut didapat Mean (Skor rata-rata) $=75,35$, Median (Skor tengah) $=76,9$, Modus (Skor yang sering muncul) $=76,9$,Standar Deviasi $($ simpangan baku $)=9,14$.

Tabel 1. Kelas Kontrol

\begin{tabular}{cccc}
\hline Kelas & Interval & Frekuensi & \% Frekuensi \\
\hline 1 & $61,5-66,5$ & 7 & 21,8 \\
2 & $67,5-72,5$ & 3 & 9,4 \\
3 & $73,5-78,5$ & 11 & 34,4 \\
4 & $79,5-84,5$ & 8 & 25
\end{tabular}




\begin{tabular}{cccc}
\hline & & 3 & \\
Jumlah & $85,5-90,5$ & 32 & 9,4 \\
$100 \%$ & \\
\hline & \multicolumn{2}{c}{ Tabel 2. Kelas Experiment } \\
\hline Kelas & Interval & $\mathbf{F i}$ & $\mathbf{\% F}$ \\
\hline 1 & $53,8-57,8$ & 14 & $42,4 \%$ \\
3 & $58,8-62,8$ & 8 & $24,3 \%$ \\
4 & $63,8-67,8$ & - & - \\
5 & $68,8-72,8$ & 4 & $12,1 \%$ \\
6 & $73,8-77,8$ & 7 & $21,2 \%$ \\
\end{tabular}

Hasil belajar akuntansi pada kelas eksperimen kategori sangat baik ada 22 orang (68,75\%), dan kategori baik ada 10 orang $(31,25 \%)$. Dari deskripsi data hasil belajar akuntasi kelas eksperimen siswa kelas XI IPS 5 SMA Negri 5 Kota Jambi. Deskripsi data tentang hasil belajar kelas kontrol diperoleh dari subjek penelitian yang berjumlah 33 siswa dengan skor antara 53,8 sampai 76,9. Hasil analisis diperoleh Mean (Skor rata-rata) $=62,8$ Median (Skor tengah $)=61,5$, Modus $($ Skor yang sering muncul $)=61,5$, Standar Deviasi $($ simpangan baku $)=7,68$. Untuk melihat frekuensi variabel hasil belajar memperoleh skor hasil belajar akuntansi skor 53,8 sampai dengan 57,8 ada 14 orang $(42,4 \%)$, yang memperoleh skor 58,8 sampai dengan 62,8 ada 8 orang $(24,3 \%)$ yang memperoleh skor 63,8 sampai dengan 67,8 ada 0 orang (- orang), yang memperoleh skor 68,8 sampai dengan 72,8 ada 4 orang (12,1\%), yang memperoleh skor 73,8 sampai dengan 77,8 ada 7 orang $(21,2 \%)$. hasil belajar akuntansi pada kelas kontrol kategori sangat baik ada 7 orang $(21,21 \%)$, dan kategori baik ada 26 orang $(78,79 \%)$. Dari deskripsi data hasil belajar akuntasi kelas kontrol siswa kelas XI IPS 3 SMA NEGR1 5 KOTA JAMBI berada pada kategori baik dan sangat baik.

Berdasarkan hasil penelitian melalui tes akhir pilihan ganda dengan 5 pilihan jawaban (a, b, c, d dan e) dari 30 butir soal yang akan direncanakan, setelah diujicobakan pada kelas XI IPS ternyata setelah dianalisis dari 30 soal hanya 26 soal yang bisa dipakai kemudian dilakukan untuk menguji kemampuan pada kedua kelas sampel.

Penelitian ini dilakukan dengan menggunakan eksperimen semu (quasi eksperimental) dengan bentuk desain pre test (tes awal) dan post test (tes akhir) dengan kelompok pengendalian tidak diacak. Dalam desain ini subjek tidak diacak karena dalam situasi sekolah tidak memungkinkan untuk mengubah kelas atau siswa, maka peneliti menggunakan kelas yang ada.

Penelitian quasi eksperimen dapat diartikan sebagai penelitian yang mendekati eksperimen atau eksperimen semu. Bentuk penelitian ini banyak digunakan dalam bidang ilmu pendidikan atau penelitian lainnya dengan subjek yang diteliti adalah manusia, di mana mereka tidak boleh dibedakan antara satu dengan yang lain seperti misalnya dengan mendapat perlakuan karena berstatus sebagai grup kontrol. Pada penelitian quasi eksperimen peneliti dapat membagi grup yang ada dengan tanpa membedakan antara kontrol dengan grup secara nyata dengan tetap mengacu pada bentuk yang sudah ada.

Penelitian ini dilaksanakan di SMA Negeri 5 Kota Jambi yaitu siswa kelas XI IPS tahun ajaran 2015/2016. Pelaksanaan penelitian sesuai dengan jadwal pelajaran yang telah ditetapkan. Pelaksanaan pembelajaran dilaksanakan sebanyak 7 kali pertemuan, dimana pada pertemuan pertama untuk pelaksanaan tes awal, pertemuan ke II-VI ( 6 kali pertemuan) untuk perlakuan, dan pertemuan ke VII untuk tes akhir.

Berdasarkan data awal penelitian yaitu nilai pretest, menunjukkkan bahwa rata-rata kelas eksperimen dan kelas kontrol relatif sama. Hal ini ditunjukkan dari data pretest kedua kelas tersebut. Pada kelas eksperimen rata-rata kemampuan awal 50,59 sedangkan pada kelas kontrol rata-rata kemampuan awal 49,64. Hal ini menunjukkan bahwa antara kelas eksperimen dan kelas kontrol mempunyai kemampuan yang relatif sama.

Dari perhitungan statistik dapat dilihat bahwa nilai rata-rata hasil belajar siswa pada mata pelajaran akuntansi di kelas XI IPS pada kelas eksperimen lebih besar dibandingkan dengan perolehan nilai pada kelas kontrol, hal ini disebabkan dari perlakuan yang diberikan. Pada kelas eksperimen yang diajar dengan menggunakan model pembelajaran berbasis Collaborative learning diperoleh nilai rata- rata $(X)=75,35$ simpangan baku $(S)=9,14$ dan varian $(S 2)=83,64$. Sedangkan pada kel Kontrol diajarkan tMak menggunakan model pembelajaran secara konvensional diperoleh nilai rata-rata $(X)=62,8$ simpangan baku $(S)=7,68$ dan varian $(S 2)=59,00$. Dengan hasil hipotesis thitung $>$ ttabeL atau $(5,048>2,039)$, dengan demikian rata-rata hasil belajar post-test belajar, simpangan baku, varian dan hipotesis kelompok eksperimen berbeda secara signifikan dari kelas kontrol.

\section{SIMPULAN}

Berdasarkan hasil analisis data dan pengujian hipotesis. maka dapat disimpulkan bahwa rata-rata hasil belajar akuntansi siswa kelas XI IPS yang diajarkan dengaii menggunakan model pembelajaran berbasis Collaborative Learning adalah 75,33 lebih tinggi dibandingkan dengan rata-rata hasil belajar siswa kelas XI IPS pada mata 
pelajaran akuntansi yang diajarkan secara konvensional adalah 62,8. Hasil uji t-test diperoleh hasil kooefisien thitung $>$ ttabel atau 5,048 > 2,039. Dengan demikian dapat diartikan terdapat pengaruh penggunaan model pembelajaran berbasis Collaborative Learning terhadap hasil belajar akuntansi siswa kelas XI IPS SMA Negeri 5 Kota Jambi. Dimana dengan pembelajaran menggunakan model pembelajaran Collaborative Learning di kelas eksperimen lebih aktif dibandingkan dengan kelas control yang menggunakan carakonvensional. Dapat dikatkaan berpengaruh apabila t hitung lebih besar dari t-tabel.

Kepada semua pihak terutama guru bidang studi ekonomi/akuntansi agar dapat menggunakan model yang bervariasi dalam proses belajar mengajar, salah satunya dengan menggunakan model pembelajaran berbasis Collaborative Learning, karena model ini akan mengarah pada proses perbaikan dan peningkatan kemampuan siswa dalam menerima materi pelajaran dikelas, dan proses belajar mengajar menjadi menyenangkan dimana dengan melakukan pembelajaran secara kolaborasi infomiasi tidak hanya bersumber dari guru atau buku pelajaran saja, tetapi teman juga dapat memberikan informasi sebagi tempat untuk bertanya.

\section{DAFTAR PUSTAKA}

Arikunto. 2002. Metode Penelitian dan administrasi pendidikan. Bandung: Alfabeta

Bloom, Supriyono. 2010. Kriteria keberhasilan belajar. Jakarta: PT. Galia Indonesia

Djamarah. 1997. Strategi Belajar Mengajar. Jakarta: Raja Grafindo

Djamarah dan Aswan. 2002. Strategi Belajar Mengajar. Jakarta: Rineka Cipta

Didik. 2002. Upaya peningkatan mutu pendidikan indonesia. Jakarta : Raja Grafindo

Hamalik. 2003. Perencanaan Pengajaran Berdasarkan Pendekatan Sistem. Jakarta: Bumi Aksara.

Kardiman. 2006. Prinsip-prinsip Akuntansi1SMA kelas XI . Jakarta: Yudhistira

Marianus. 1998. Prinsip-prinsip Akuntansi 1SMA kelas XI. Jakarta: Yudhistira.

Munadi. 2010. Belajar dan Faktor-Faktor yang Mempengaruhinya. Jakarta: Rineka Cipta.

Mona Efri Handayani. 2013. Penggunaan media pembelajaran berbentuk permainan card sort terhadap hasil belajar akuntansi siswa kelas XI IPS SMA Negeri 11 Kota JambiPIPS FKIP. UNJA: Skripsi.

Ristanti. 2003. Pengantar Akuntansi. Jakarta: Raja Grafindo.

Rusman. 2010. Prinsip-prinsip Akuntansi 1 SMA kelas XI . Jakarta: Yudhistira

Rusy'an. 1993. Strategi Belajar Mengajar. Jakarta: Raja Grafindo

Sjarkawi. 2007. Psikologi Pendidikan. Jakarta: Departemen Pendidikan dan Kebudayaan

Slameto. 2010. Strategi Belajar Mengajar. Jakarta: Raja Grafindo

Slavin, 2006. Model Pembelajaran Kooperatif Tipe STAD,Jakarta: Nusa Media

Soedarto. 1997. Kriteria keberhasilan belajar. Jakarta: PT. Galia Indonesia

Soewarso. 1998. Model pembelajaran Collaborative Learning. Jakarta: PT. Phibeta Aneka Gama.

Sudibyo. 2006. Prinsip-prinsip Akuntansi1SMA kelas XI . Jakarta: Yudhistira

Sudjana N. 1990. Penilaian Hasil Proses Belajar Mengajar. Bandung: Remaja Rosda Karya

Sugiyono. 2010. Psikologi Belajar. Jakarta: Raja Grafindo Persada. Bandung: Alfabeta.

Syah Muhibbin. 2003. Psikologi Pendidikan dengan Pendekatan Baru. Bandung: Rosda Karya.

Yamin, M. 2007. Startegi Pembelajaran Berbasis Kompetensi. Jakarta: Gaung Persada Pers. 